OrTAR N., VinCENT-GeSLIN S., BOUdREAU J.A., "The youth on the move: French and Canadian young people's relationship with the car", Journal of Applied Mobilities, 2018,

\title{
The Youth on the Move: French and Canadian Young People's Relationship with the Car
}

Nathalie Ortar, LAET/ENTPE/CNRS/Université de Lyon, Rue Maurice Audin, 69518 Vaulxen-Velin cedex - France, nathalie.ortar@entpe.fr

Stéphanie Vincent-Geslin, LAET/ENTPE/CNRS/Université de Lyon, 14 rue Berthelot, 69007 Lyon - France

Julie-Anne Boudreau, INRS, 385, rue Sherbrooke Est, Montréal (Québec) H2X 1E3 - Canada

\section{Translated from the French by Cadenza Academic Translations}

Use of the car depends as much on whether it arises due to symbolic or affective factors as to pragmatic ones (Steg 2005). It occupies a central place in the mobility and lifestyles of the majority of adults and has "reshaped citizenship and the public sphere via the mobilisation of modern civil societies" (Sheller and Urry 2000). However, the first decade of the 2000s was one of changes, signalling ruptures in major trends in the evolution of the role of the car (Goodwin and Van Dender 2013, Metz 2010). Young people are particularly affected by these changes, the result of which has been a reduction in the number of individuals holding a driving licence and of the use of the car in a number of western nations (Delbosc and Currie 2013, Hjorthol 2016, Kuhnimhof, Armoogum, et al. 2012, Pooley, Turnbull, and Adams 2005, Roux 2012, Vincent-Geslin et al. 2017). These changes raise the following question: how might one explain this decreased interest on the part of young people with regard to obtaining a driving licence and using a car?

In order to understand the nature of the ongoing changes, we will analyse, within the context of this article, the social and symbolic roots behind this reduction in the obtaining of driving licences, and a decreased interest in driving, based on a piece of Franco-Quebec research carried out in Lyon and Montreal ${ }^{1}$, describing changes in the relationship between young people and cars in two contexts that are similar with regard to access to mobility services. Both metropolitan areas have efficient public transport systems, bike-sharing services, carsharing services and carpooling, but are set apart nonetheless by a difference in the number of driving licences obtained. In France ${ }^{2}$ as in Quebec, ${ }^{3}$ individuals are permitted to drive from the age of 16 onwards. Nevertheless, at the time in which this survey was carried out, young

\footnotetext{
${ }^{1}$ These pieces of research were carried out under the framework of the EvolMob project, a Franco-Quebec research project financed by the Forum Vies Mobiles and jointly led by the Transport, Urban Planning and Economics Laboratory (Lyon), the Institut National de la Recherche Scientifique (Montreal) and the École Polytechnique de Montréal.

${ }^{2}$ This refers to the "accompanied driving" measure. The Macron Law of August 2015, having been implemented after the research was carried out, modified the minimum age for access established within the measure. It is now possible to start the learning process from the age of 15 and to take the practical exam at the age of 17 and a half. Source: https ://www.service-public.fr/particuliers/vosdroits/F2826, accessed on 24 January 2017.

${ }^{3}$ The driving licence is not awarded at a national level but by the government of the province, thus Quebec in the case of Montreal.
} 
French people had to wait until they reached the age of 18 in order to be able to drive alone. In France, to obtain the driving licence, candidates have to register at a driving school and then pass a theory test (the rules of the road) and a practical driving test after having spent at least twenty hours driving, accompanied by an instructor. The cost was estimated at around $€ 1,600$ in 2014 . $^{4}$

In Quebec, obtaining a driving licence comes about in three stages. The first of these results in the approval of an individual's 'learner licence' after completing driving theory lessons at a recognised driving school. This learner driving licence gives individuals the right to drive with an instructor who has been in possession of a licence for more than two years. The theory test takes place at least ten months after the learner driving licence has been obtained and the practical test follows another twelve months after the theory test. Young drivers then obtain a provisional licence, which means that they are no longer required to be accompanied by a third party. However, traffic offences are less tolerated and there is zero-tolerance of drink driving. Over a period of twenty-four months, this provisional licence is converted to a full driving licence. ${ }^{5}$ Despite the requirement that lessons be taken, the cost of obtaining one's driving licence in Canada is half of what it costs in France.

\section{Different Explanatory Hypotheses}

The general hypothesis for explaining the decreased level of interest among young people with regard to getting a driving licence and using a car is that new generations that have reached the stage where they are financially independent view the various modes of transport in a more practical way, as elements that complement broader lifestyles (Hjorthol 2016), an attitude made possible by the redeployment of public transport services, the emergence of new mobility services, the greater focus on physical activity, and the renewed interest in carpooling (Hjorthol 2016, Grimal, Collet, and Madre 2013, Oldenziel et al. 2016). The increase in new consumption practices was also at stake here. Favourable attitudes towards new technologies and the possibility of conducting online relationships, purchases, or other activities carried out at a distance, and without the need for mobility, thus constitutes an explanation for a decrease in physical mobility (Aguiléra, Guillot, and Rallet 2012, Le Vine, Latinopoulos, and Polak 2014). This hypothesis has, nonetheless, been contested by analyses of youth mobility (Delbosc and Currie 2013, Massot and Zaffran 2007, Devaux, Oppenchaim, and Proulhac 2016).

Economic factors are also presented as being at the heart of these changes in behaviour. Indeed, since the 1990s, numerous western countries (Kuhnimhof, Zumkeller, and Chlond 2013, Delbosc and Currie 2013), among them France and Canada, have reinforced the knowledge base and skills necessary for obtaining a driving licence. These changes have had an impact on its overall cost (Raimond and Milthorpe 2010) in a context of economic recession and difficulties vis-à-vis professional integration in a number of countries, including France. The reduction in the numbers of those obtaining a driving licence is thus revelatory of growing social inequalities (Licaj et al. 2012).

This evolution emerges within a context of an increase in the length of the period of youth (Shanahan 2000, Van de Velde 2008), this being connected to a transformation of the stages

\footnotetext{
4 Source: http://www.interieur.gouv.fr/Actualites/Dossiers/Reforme-du-permis-de-conduire-priorite-jeunesse, accessed on 24 January 2017.

${ }^{5}$ Source: http ://www.saaq.gouv.qc.ca/permis/permis_promenade.php, accessed on 24 January 2017.
} 
of transition towards independence from one's own family. These stages include sexuality, partnership and parenthood, lifestyle, and citizenship, all of which "follow their own logic and progress according to their own rhythms with specific obligations" (Research 2001). This is reflected in particular by a report on the birth of children, who are at the root of different mobility needs (McLaren 2016). Moreover, the reduction in numbers obtaining a driving licence may only be a delay, a gap that may progressively close, although it does appears likely that the rate of obtention will remain lower than in the past (Frändberg and Vilhelmson 2011, Nordbakke, Sagberg, and Gregersen 2016). The reduction in the obtention of driving licences among young people is, in this sense, the result of social effects connected to the economic and learning contexts, to an evolution of socialisation of young people to mobility as a consequence of the lengthening of the period of youth.

\section{Methodology}

While creating our sample, we had to take four elements into account. The first is that, overall, the recent history of the driving licence has been marked by a gender discrepancy, this being gradually bridged by women (Kuhnimhof, Armoogum, et al. 2012, Vincent-Geslin et al. 2017). The second is that the relationship with the car is socially differentiated, something that leads to a particular culture of repairing and transforming of cars for young people from working class backgrounds (Bengry-Howell and Griffin 2007, Gossiaux 1992). The third is the existence of subcultures that differ between districts (Shildrick 2006) and, above all, between rural and urban areas (Farrugia 2014). Finally, the fourth element-which has already been mentioned - relates to the desynchronisation of the transition stages towards adulthood (Furlong and Cartmel 2007, Research 2001).

Around fifty interviews were conducted with young people aged 16 to 35 in Lyon and Montreal. The age of 16 was defined as the lowest range of the sample, as it is the minimum age required to gain access to accompanied driving. The highest age range of the sample was set at 35 so as to take into account the role played by the changing of stages in an individual's life cycle (i.e. professional integration, settling down, birth of a child) on the relationship of young people with the car, given that the average age at which a couple has their first child is 30 in France (Pison 2010) as in Quebec (ISQ 2016). A diversity principle was applied in the creation of the sample, in particular with regard to residential habitation (centre, suburbs, periphery, etc.), social origins, and gender. Age diversity within the category, as well as educational and professional contexts, were also taken into account.

The young people interviewed were contacted through various channels. First of all, we made use of the method known as the "snowball", which consists of mobilising the social networks of the surveyors so as to get in touch with potential volunteers for interviews. The advantage of this method is that it is a quick and effective means of getting in touch with the surveyed persons, making it more likely that individuals will participate in the survey and building a relationship of trust in an interview setting. Secondly, certain young people were found through the intermediary of a web questionnaire on mobility trends, at the end of which they left their contact details in order to be contacted again later. This complementary means of recruitment allowed us to expand our recruitment networks and to target users of alternative means of transport such as car sharing, carpooling and self-service bicycles, or according to specific profiles - notably age, work situation or place of residence. Thirdly, to compensate for the difficulty of finding very young interviewees from working class backgrounds, the assistance of schools located in disadvantaged areas was requested. 


\section{A Weakening of the Driving Licence Norm?}

In order to illustrate the unquestioned norm that taking the driving test represented-affecting almost the entirety of an age group - we point out that the literature describes it as a rite of passage towards adulthood in France (Gossiaux 1992, Masclet 2002) as in Canada (Tilleczek 2004). In both countries, for the oldest interviewees, learning to drive was seen as a given. Thus, Élise (30, bike, physiotherapist, Lyon) reports that: "I think that it was the normal thing to do. At the age of 18, you take your driving test." This norm was strongly influenced by couples (Gossiaux 1992, Tilleczek 2011). Nonetheless, our survey presents indicators that illustrate a weakening of this norm.

Currently, in Lyon as in Montreal, there is an awareness that holding a driving licence is important in order to be able to access one's workplace, go on holiday, do one's share of the driving during long journeys, or getting from one place to another with a child in cases of emergency. Taking one's driving test is an asset, an investment for the future that opens up possibilities, notably in terms of professional life, as Léo (20, car and public transport, worker, Lyon) remarks: "Even though I didn't have a vehicle, simply putting on my CV that I had a licence was helpful in some cases." This is a reality that catches up with young people when they are confronted with this need when in search of their first job. According to Louis (18, vélo'v, ${ }^{6}$ student, Lyon): “Last summer, when I was looking for a summer job for a month, I found that all the jobs were with companies located outside of Lyon and that without a driving licence I wouldn't get very far." This is even truer if they are applying for low-skilled jobs that are based on the fringes of urban areas (Korsu and Wenglenski 2010, Ortar 2016). Nevertheless, these familiar factors for young people are not enough to make them take their driving test, something which may be interpreted as a first indicator of the weakening of the norm.

\section{A Diminishing Norm in French Urban Centres}

The second indicator is the significance of the prescriptive role of parents in Lyon, something that has been reported by Candice (23, bike sharing, student, Lyon): "[My parents] imposed it on me. They told me it was necessary for later in life, that at the moment in time when I would need it, I'd have it." This regularly observed attitude contrasts with the case of Montreal, where parents support their child's initiative to learn to drive but do not finance it very much and do not impose it. In fact, the norm of taking one's driving test seems more visible in Montreal, where, out of all the young people interviewed, only one person over the age of 18 did not have their driving licence. The reaction of this individual's close relatives with regard to her situation is revealing of the importance still attached to obtaining the driving licence: "Everyone laughs at me in my family because I'm 29 years old and I still don't have my driving licence" (Martine, public transport, student, Montreal). In Lyon, this transgressive dimension is not as apparent, as the case of Clément (23, public transport, student, Lyon) shows. He spent all of his childhood in New Caledonia, where there is no transport alternative to the use of the car. Having come to Lyon to study at the age of 19, he never felt the need to take the driving test, and as such is the only one of his siblings that has not learned to drive.

\footnotetext{
${ }^{6}$ Translator's note: This refers to the self-service bike sharing system that is currently in operation in the urban areas of Lyon and nearby Villeurbanne.
} 
The weakening of the norm in Lyon is to be understood within a context of a general decline with regard to dual car ownership in urban areas in France. Thus, the youngest urban dwellers in Lyon coming from the middle and upper classes have been socialised within families where single car ownership among parents is the norm (Grimal, Collet, and Madre 2013). It must also be noted that for young urban dwellers, independence in terms of mobility occurs from around the age of 15 (Devaux and Oppenchaim 2013, Massot and Zaffran 2007). By the time they take their driving test, these young people have already developed a strong socialisation to public transport and have become accustomed to travelling using their own means.

\section{The Temporal and Financial Costs that Constrain the Obtention of a Licence}

In Montreal, the driving licence has been perceived as a costly learning endeavour since the introduction of the most recent law, a factor which strongly encouraged young individuals to obtain it as quickly as possible: "I got my licence before the new law on licences came into effect. The law that required you to be...that you must complete one set of lessons for the theory part and another set for the practical part. I didn't want to spend that much money on it." (Solange, 23, public transport, student, Montreal). Nonetheless, despite this modification of the law, whether they are young residents living in the centre of cities or on the outskirts and regardless of family income, all of these young people are focussed on obtaining their licence, or plan to get it soon. Financing it is achieved through odd jobs or is provided for them, particularly as a "Christmas present" (Julie-Anne, 16, public transport, student, Montreal).

In Lyon, the majority nonetheless mention that their licence was provided for them by close relatives - parents, grandparents, godfathers and godmothers-except with regard to those coming from the most deprived social backgrounds, where the cost constitutes an obstacle towards obtaining it. Taking the driving test thus represents a significant expense and not all individuals manage to finance it. Brian (18, public transport, student, Lyon) is a full-time student. His mother is a cleaning lady. Despite their tendency to save money, they proved to be incapable of getting the necessary funds together at the time of the survey. Taking the driving test is thus postponed and it will be financed by money earned over the course of his first job or "odd jobs" carried out over the holidays.

In this context, having close relatives finance one's driving licence ought to be particularly motivating. For young urban dwellers, this, nevertheless, does not prove to be sufficient to compensate for its other cost, this one being time-related: "To take your test, you need to have time and cash!" as Anissa (22, public transport, student, Lyon) concludes. Getting the driving licence is considered time-consuming and does not fit in easily with the process of pursuing one's education. Such recurring references by young people in Lyon to the temporal stranglehold represented by studies is interesting since this alone is revealing, on the one hand, of the fact that the driving licence is subject to arbitrage between different social activities and, on the other, that it is an audible response directed at parents who, in a context of chronic employment crisis and academic competition (Dubet, Duru-Bellat, and Vérétout 2010), are particularly aware of the need to facilitate their children's success.

The decline in the taking of the driving test thus masks contrasting realities between urban youth coming from the middle and upper classes who do not have need of it and young people coming from working class backgrounds who cannot afford it, a disparity of access that is representative of increasing social inequality (Coutard, Dupuy, and Fol 2004, Korsu and Wenglenski 2010). 


\section{Except for Girls from Working-Class Backgrounds}

Within this spectrum, there is a contrast in attitudes among young female urban dwellers from working-class backgrounds. They constitute the only category of females within an urban setting that continues to show a strong desire to take their driving test. Two factors explain this attitude. The first is the dependence of their mother on their father and/or on transport to get around in most cases, since women from these social groups are even less likely to drive than the average woman. The second is the lesser mobility of adolescents from working class backgrounds, a mobility that has been in decline even over the last twenty years, while young girls from the middle and upper classes move around more than before in an autonomous fashion using public transport (Devaux, Oppenchaim, and Proulhac 2016) and thus confirming the maintenance of a gender gap observable through the practice of mobility (Hjorthol 2008). We are thus witnessing a double phenomenon with, on the one hand, young girls being more autonomous than in the past, and also strongly socialised to multi-modal transport. On the other hand, there are young girls whose mobility potential has diminished. In these conditions, the driving licence represents a mobility tool. Obtaining one's driving licence and going from place to place by car constitutes a means of escape from dependence - their mobility being otherwise subject to the wishes of their future spouse or their close relatives - and a quest for independence with regard to their current circumstances. Nevertheless, this desire for access to automobility comes up against the cost of financing a driving licence and subsequently a vehicle, this being even more the case if they come from households where driving is not the usual means of transport.

\section{Regarding Peri-Urban Youth}

This first category also requires a degree of nuance with regard to residential habitation. For young people who live in peripheral (suburban and peri-urban) areas, or even rural areas, whether it is in France or in Quebec, where dependence on cars remains strong, taking the driving test when one reaches the required age remains the norm, being seen as necessary and thus taken for granted. Éduard (28, public transport, transport coordinator, Montreal) who spent his childhood on a farm in an isolated region in the north of Quebec, explains: "Well, at Saguebay, it was the thing to do when you were 16, you... [...] Everyone took their driving test...." In a similar manner, Amélie (27, carpooling and car user, marketing, Lyon), who grew up in the region of Mâcon, a small town located considers that: "Not passing the driving test in the countryside is like being an extra-terrestrial." The perception that the holding of a driving licence is necessary is directly linked to the lack of existing alternatives for getting around. This exclusively car-related socialisation is reinforced in both countries through a precocious access to driving in these areas, where close relatives who drive teach young people to drive without necessarily going through a driving school, such as in the case of Igor (29, bike, student, Montreal): "I used the car...when I was young-aged 13, aged 12-when I went to my grandparents' house, my grandad would let me drive his car, only there. I used to take his car keys and go for a spin." This is a socialisation that is also reinforced by male driving culture and that persists among young men (O'Connor and Kelly 2006), something that Romain (34, public transport, unemployed, Lyon) testifies to: "In my rural environment, in the villages, having a car is everything [deep voice], you fix it up a bit, you turn the music up to full volume."

If the cost of access is just as commonly spoken of in France, it occurs in referring to the necessary saving that has been carried out by parents and/or the young person in order to finance the obtention of the licence. Within a similar social milieu, the investment proves to 
be, thus, very different. Also, the temporal constraint represented by the learning process is not brought up. Through their desire for their children to be independent with regard to their mobility, parents are shown to be even more prescriptive than in an urban setting. We therefore take note of a mixture of conventional trends and a strong sense of encouragement, leading one to believe that while a change in attitude with respect to the driving licence may be underway, this is not yet noticeable in actual practice.

\section{Evolutions in the Uses of Automobility}

Taking one's driving test does not necessarily imply owning one's own vehicle or driving regularly. This dimension separates the young people interviewed from preceding generations. During the period of youth of the latter, a strong link between licence, ownership and use was to be noted (Vincent-Geslin 2010). While the oldest age group within the survey had the option to use a family car and were often given or offered a car by a member of their family ${ }^{7}$, or acquired vehicles with money earned through the performing of "odd jobs," this is only rarely true of the youngest individuals, who, even in a rural setting, only have restricted access to their parents' car or those of their brothers and sisters, as long as they continue to live within the family home. Young people in Quebec, nevertheless, seem to have a somewhat greater level of access to cars than their counterparts in France. Being less likely to drive, young people also appear to be less likely to use a car than the generations that came before them (Ortar and Vincent-Geslin 2017, Kuhnimhof, Buehler, et al. 2012).

\section{The Car Is No Longer as Much a Symbol of Freedom and Autonomy as It Was in the Past}

Young urban dwellers question the link between the car and freedom. One such questioning individual is Martine (29, public transport, student, Montreal): "I think that what limits autonomy is thinking you are not autonomous. That's it really. It's in your head, in fact." For Martin (29, car, student, Montreal) the need for the car, particularly to stock up on goods, is no more than an "urban myth." Young people residing in urban areas have a negative perception of ownership and the use of a vehicle in the city centre, as well as a precise estimation of the costs involved. Thomas (20, public transport and scooter, wage-earning student, Lyon) mentions the fact that his friends who have cars "struggle in the city centre." While he took his driving test during the period of time in which the survey was carried out, he maintains that: "it is not necessarily a question of using it right away" since driving a car, and also parking it, cost quite a lot. The perception of a forced use of the car is given added weight by the presence of an alternative mode of transport in Lyon as in the centre of Montreal, deemed to be more effective than the car for getting around.

\footnotetext{
${ }^{7}$ Numerous pieces of research show that, in rural areas, an old car was often given to young driving licence holders, even in working class families (Gossiaux 1992).
} 


\section{Alternative Uses}

Among the young people interviewed for the survey, few daily car users are to be observed. Whether their main mode of transport is a bicycle or public transport, most young people interviewed have their licence already or are in the process of getting it. The car thus forms part of the "portfolio of access" of young people (Flamm 2004), even though few of them end up using it on a daily basis. The use of transport alternatives, dominant among young people, reflect the effects of public policies that promote public transport, bike sharing and the transformation of access to the city for the benefit of pedestrians and cyclists, as Mathieu (27, bike, unemployed, Lyon) notes: "It's all about the bike, you can see more and more people on bikes, in any case. I think that what made the use of bicycles popular in Lyon is the vélo'v. People who didn't necessarily have a bike have now started cycling." Furthermore, in Montreal as much as in Lyon, bikes parked beside metro or train stations testify to multimodal uses, combining several modes of transport within a single journey.

These alternative transport users draw on a recreational and hedonistic view of the journey time that offers the opportunity to relax or to engage in other activities. Typical of this is Sophie (35, public transport and car user, middle manager): "On the bus, I like listening to music. I'm in my own bubble, and I like listening to music in order to unwind, especially after work." This freed-up journey time also correlates with the use of smartphones, as Arthur (25, public transport, student, Lyon) explains: "There is the added comfort of letting yourself go, of being able to reflect, being able to text...." Transport time is therefore reappropriated for carrying out other activities. As Arthur highlights, there is a real sense of comfort to be got from switching off in order to find time for yourself before going home, continuing to work, or simply communicating. The break obtained through mobility, facilitated by comfortable public transport, gives time a new value.

\section{A More Shared Use of the Car}

In both metropolitan areas, a shared use of cars is to be observed. Carpooling is thus a wellrecognised practice in Lyon as in Montreal. The majority of young people interviewed, with the exception of the very young (aged 16/17), have experimented with journey sharing, whether this was over a long distance - for going on holiday-or visiting close relatives. Thus, Tutuka (26, bike, student, Montreal) explains that he used carpooling in order to visit his friends. Likewise, Mathieu (27, bike, unemployed, Lyon) shared his journeys to a great extent when he was coming back from his long-distance work-related travel for the weekend. The young people interviewed use this journey-sharing scheme as passengers as well as drivers when they have a car. In the Lyon survey, three people were even involved in a home to workplace carpooling scheme. These results reflect the broad popularity of carpooling in France over the last number of years.

Car sharing is a relatively well recognised transport option in Montreal, unlike in Lyon. This difference can perhaps be explained by the length of time that the Communauto service - the main Montreal-based car-sharing service, established in 1994-has been in operation. Of equal relevance here, however, is the lower number of young urban dwellers in Lyon who have a licence. In Montreal, Mina (26, public transport, urban transport planning technician, Montreal), a subscriber to Communauto, stopped using her car so as to sign up to the service. She describes this solution as being less onerous and restricting as it guarantees the

\footnotetext{
${ }^{8}$ Bike sharing system.
} 
availability of a vehicle without fixed cost charges, the issue of parking, and maintenance. These advantages of car sharing are described by other young people from Montreal. This system is particularly attractive to non-driving young holders of driving licences who live in the city centre, due to its inexpensiveness. One example of this is Simone (27, bike, event coordinator, Montreal). She is like the majority of young people that fall within this category in Montreal, who see themselves as not being able to afford a car, a cost that is often weighed up against the expected benefits: "I find it [a car] expensive and that the cost does not match the advantage it offers." (Claudia, 25, bike, student, Montreal).

\section{The Association between Having a Car and Professional and Family Constraints}

Not having access to a car (whether it is one's own or belonging to one's household), remains a constraint that is linked to dependence on bus timetables and on public transport services, to difficulties when it comes to travelling with children, and to a greater feeling of discomfort (especially in winter). Start and finish times at work may prove to be incompatible with public transport timetables and workplaces may be located in areas that are not easily accessible without a car. Léo (20, car and public transport user, worker, Lyon) therefore has his own car, something which he could not manage without due to work reasons. Likewise, Mabel (35, public transport and car user, administrative agent, Montreal) decided to buy a car of her own to get to her workplace when she lived in Laval, since her journey times were too long via public transport.

Having a vehicle of one's own is also strongly associated with parenthood. The mothers interviewed in Lyon as in Montreal have a family vehicle at their disposal, even though they are not always the main drivers. Nonetheless, as in other urban centres (McLaren 2016), their transport practices - when they live in the city centre - remain highly multi-modal, as Ingrid, who gets around by bike on a daily basis, reports: "[The car] We use it a little bit more, perhaps, with the little one because... After that, we don't use it. In the evening, we say to ourselves: well, it'd be a bit of a pain in the metro with him, the buggy, so we take the car... When we go over to friends' houses, for example, when we have the travel cot, well, em, yes, we take the car" (Ingrid, 32, bike, physiotherapist, Lyon). The car is helpful and serves a particular function but is not viewed as a pleasant mode of transport by those who have children and cannot avoid using it. This tense relationship with the car leads to choosing alternative forms of transport wherever possible.

\section{Choices in Residential Habitation}

This transformation of habits also affects peri-urban residents. While all individuals that work have a vehicle, and households generally have two cars, alternative practices exist also. Aline (28, public transport and car user, technician, Lyon) lives in a peri-urban area near her partner's job. He gets to work by bike. She herself uses the train and public transport to get to work. Their vehicle is used at the weekend to meet friends, as taking the train proves to be too restrictive in the evening. Amélie (27, carpooling and car user, marketing, Lyon) lives in a peri-urban area and works in an industrial area not served by public transport. Every day, Amélie goes on her own, by car, to the fixed meeting point that is five kilometres away from where she lives. She then carpools with one other person who lives in a neighbouring district and who works in the same area. Thus, an evolution is also to be noted in peri-urban areas where, even though car ownership remains higher than in city centres, a variety of transport uses are emerging. 
Having a car of one's own is thus strongly linked to spatial constraints with regard to mobility and to life cycle (Clark, Lyons, and Chatterjee 2016). This leads to the making of certain choices - albeit not necessarily permanent ones - even though those who drive cars mention how difficult it can be to change their habits.

\section{Conclusion}

An analysis of the obtention of the driving licence offers a contrasting picture with that of Lyon, where a weakening of the norm can be observed among young people from the middle and upper classes, as well as a lower rate of test taking, this being attributable to the precariousness of the economic situations of the working classes. Two completely distinct factors can thus be identified that relate on one hand to a transformation of social practices of the middle and upper classes and, on the other, to a lack of any job security within the poorer neighbourhoods. In Montreal, an increase in the cost of taking the driving test does not seem to have had an impact on the norm, which continues to prevail with regard to young people, broadly speaking. On the other hand, a similarity emerges between the two metropolitan areas with regard to transport practices and forms of mobility. In both cases, early socialisation to other forms of transport and the quality of public transport services prove to be strongly incentivising factors with respect to adopting a lifestyle in which the car plays only a minor role.

Through our analysis, a pragmatic relationship with the car emerges. While it remains a necessity for people living in peri-urban areas - this being true of both metropolitan areasthe majority of young people would rather opt out of using it due to the high costs involved. There is also a general lack of appetite for the use of the car to be observed on both sides of the Atlantic, motivating people to look for alternative mobility solutions. This finding reinforces the hypothesis that the current changes will persist in spite of evolutions in the human life cycle.

\section{Bibliographical References}

Aguiléra, Anne, C Guillot, and A Rallet. 2012. "Mobile ICT and physical mobility; review and research agenda." Transportation Research Part A 46:664-672.

Bengry-Howell, Andrew, and Christine Griffin. 2007. "Self-made motormen: the material construction of working-class masculine identities through car modification." Journal of Youth Studies 10 (4):439-458.

Clark, Ben, Glenn Lyons, and Kiron Chatterjee. 2016. "Understanding the process that gives rise to household car ownership level changes." Journal of Transport Geography 55:110-120.

Coutard, Olivier, Gabriel Dupuy, and Sylvie Fol. 2004. "Mobility of the Poor in Two European Metropolises: Car Dependence Versus Locality Dependence." Built Environment 30 (2):138145.

Delbosc, Alexa, and Graham Currie. 2013. "Causes of Youth Licensing Decline: A Synthesis of Evidence." Transport Reviews 33 (3):271-290.

Devaux, Julian, and Nicolas Oppenchaim. 2013. Teenage mobility: a socialised and socialising practice. Métropolitics. Accessed 29 novembre 2016.

Devaux, Julian, Nicolas Oppenchaim, and Laurent Proulhac. 2016. L'évolution des pratiques de mobilité des adolescents depuis 20 ans en île-de-France : quelle influence des variables sociales et territoriales sur les inégalités de genre ? Métropoles [En ligne] (18). Accessed 29 novembre 2016.

Dubet, François, Marie Duru-Bellat, and Antoine Vérétout. 2010. Les Sociétés et leur école. Emprise du diplôme et cohésion sociale. Paris: Seuil. 
Farrugia, David. 2014. "Towards a spatialised youth sociology: the rural and the urban in times of change." Journal of Youth Studies 17 (3):293-307.

Frändberg, Lotta, and Bertil Vilhelmson. 2011. "More or less travel: personal mobility trends in the Swedish population focusing gender and cohort." Journal of Transport Geography 19 (6):1235-1244.

Furlong, A, and Fred Cartmel. 2007. Young people and social change: New perspectives. Buckingham: Open University Press.

Goodwin, Phil, and Kurt Van Dender. 2013. "'Peak Car' - Themes and Issues." Transport Reviews 33 (3):243-254.

Gossiaux, Jean-François. 1992. Avoir 16 ans dans les Ardennes. Paris: Éditions du CTHS.

Grimal, Richard, Roger Collet, and Jean-Loup Madre. 2013. "Is the stagnation of individual car travel a general phenomenon in France? A time-series analysis by zone of residence and standard of living." Transport Reviews: A Transnational Transdisciplinary Journal 33 (3):291-309.

Hjorthol, Randi. 2008. "Daily mobility of men and women - a barometer of gender equality." In Gendered Mobilities, edited by T.P. Uteng and Tim Cresswell, 193-210. Farnham: Ashgate.

Hjorthol, Randi. 2016. "Decreasing popularity of the car? Changes in driving licence and access to a car among young adults over a 25-year period in Norway." Journal of Transport Geography 51:140-146.

ISQ. 2016. Le bilan démographique du Québec. Quèbec: Institut de la Statistique du Québec.

Korsu, Emre, and Sandrine Wenglenski. 2010. "Job Accessibility, Residential Segregation and Risk of Long-term Unemployment in the Paris Region." Urban Studies 47 (11):2279-2324. doi: 10.1177/0042098009357962.

Kuhnimhof, Tobias, J. Armoogum, R. Buehler, J. Dargay, J. M. Denstadli, and T. Yamamoto. 2012. "Men Shape a Downward Trend in Car Use among Young Adults, Evidence from Six Industrialized Countries." Transport Reviews:1-19.

Kuhnimhof, Tobias, Ralph Buehler, Matthias Wirtz, and Dominika Kalinowska. 2012. "Travel trends among young adults in Germany: increasing multimodality and declining car use for men." Journal of Transport Geography 23:443-450.

Kuhnimhof, Tobias, Dirk Zumkeller, and Bastian Chlond. 2013. "Who Made Peak Car, and How? A Breakdown of Trends over Four Decades in Four Countries." Transport Reviews 33 (3):325342.

Le Vine, Scott, Charilaos Latinopoulos, and John Polak. 2014. "What is the relationship between online activity and driving-licence-holding amongst young adults?" Transportation 41 (5):1071-1098.

Licaj, Idlir, Mouloud Haddak, Pascal Pochet, and M. Chiron. 2012. "Individual and contextual socioeconomic disadvantages and car driving between 16 and 24 years of age: A multilevel study in the Rhône Département (France)." Journal of Transport Geography 22:19-27.

Masclet, Olivier. 2002. "Passer le permis de conduire : la fin de l'adolescence." Agora débats/jeunesses 28 (1):46-56.

Massot, Marie-Hélène, and Joël Zaffran. 2007. "Auto-mobilité urbaine des adolescents franciliens." Espace populations sociétés (2-3):227-241.

McLaren, Arlene Tigar. 2016. "Families and transportation: Moving towards multimodality and altermobility?" Journal of Transport Geography 55:218-225.

Metz, David. 2010. "Saturation of demand for daily travel." Transport Reviews 30 (5):659-674.

Nordbakke, Susanne, Fridulv Sagberg, and Fredrik Alexander Gregersen. 2016. Slutt på lidenskapen? Endringer i førerkortandel og bilbruk blant ungdom. Oslo: Institut of Transport Economics, Norwegien Centre for Transport Research.

Oldenziel, Ruth, Martin Emanuel, Adri Albert de la Bruhèze, and Frank Veraart, eds. 2016. Cycling Cities: The European Experience. One Hundred Years of Policy and Practice. Eindhoven: Foundation for the History of Technology and LMU Rachel Carson Center for Environment and Society. 
Ortar, Nathalie. 2016. "Dealing with Energy Crises: Working and Living Arrangements in Peri-Urban France." Transport Policy. doi: 10.1016/j.tranpol.2016.09.008.

Ortar, Nathalie, and Stéphanie Vincent-Geslin. 2017. "The Decline in Car Use. A Long-Lasting Effect? French and Canadian Young Adults' Relationship with Mobility." ECEE Summer Studies, Giens.

Pison, Gilles. 2010. "France 2009 : l'âge moyen de la maternité atteint 30 ans." Populations et sociétés (465).

Pooley, Colin Gilbert, J. Turnbull, and M. Adams. 2005. A Mobile Century? Changes in Everyday Mobility in Britain in the Twentieth Century. Aldershot: Ashgate.

Raimond, Tim, and Frank Milthorpe. 2010. "Why are young people driving less? Trends in licenceholding and travel behaviour." Australasian Transport Research Forum 2010 Proceedings, Camberra.

Research, European Group for Integrated Social. 2001. "Misleading trajectories: transition dilemmas of young adults in Europe." Journal of Youth Studies 4 (1):101-118.

Roux, Sophie. 2012. "La diffusion du permis de conduire en France." Recherche Transports Sécurité 28 154-166.

Shanahan, M. J. 2000. "Pathways to adulthood in changing societies: Variability and mechanisms in life course perspective." Annual Review of Sociology (26):667-692.

Sheller, Mimi, and John Urry. 2000. "The city and the car." International Journal of Urban and Regional Research 24 (4):737-757.

Shildrick, T. 2006. "Youth Culture, Subculture and the Importance of Neighbourhood." Young 14 (1):457-465.

Steg, Linda. 2005. "Car use: lust and must. Instrumental, symbolic and affective motives for car use." Transportation Research Part A 39 (2-3):147-162.

Tilleczek, Kate C. 2004. "The Illogic of Youth Driving Culture." Journal of Youth Studies 7 (4):473-498.

Tilleczek, Kate C. 2011. "Adjusting the Rear View Mirror: An Examination of Youth Driving Culture." Youth \& Society 43 (2):774-795.

Van de Velde, Cécile. 2008. Devenir adulte. Sociologie comparée de la jeunesse en Europe. Paris: Presses Universitaires de France.

Vincent-Geslin, Stéphanie. 2010. Altermobilités, mode d'emploi. Déterminants et usages de mobilités alternatives au tout voiture. Paris: éditions du CERTU.

Vincent-Geslin, Stéphanie, Pascal Pochet, Nathalie Ortar, Patrick Bonnel, and Louafi Bouzouina. 2017. Je t'aime... moi non plus. EspacesTemps.net. Accessed 15.03.2017. 